\title{
Simulation of Assembly Tolerance and Characteristics of High Pressure Common Rail Injector
}

\author{
Jiping Lu, Shuiyuan Tang*, Yong Zhou \\ School of Mechanical Engineering, Beijing Institute of Technology, 100081 Beijing, China
}

Jing Hong

(CNGC ShanXi Diesel Engine Industry CO. LTD, 037036 Datong, China)

Zhonghua Jian

(Institute of Science \& Technology, China North Industries Group Co., 100089 Beijing, China)

Received 2 August 2011

Accepted 25 November 2011

\begin{abstract}
Fuel injector is the key part of a high-pressure common rail fuel injection system. Its manufacturing precision and assembly quality affect system's property and performance. According to the characteristics and demands of assembly of the fuel injector, an intelligent optimization algorithm is proposed to resolve the problem of assembly sequence planning. Based on geometric modeling, assembly dimension chain of the injector control chamber is established, and the relationship between assembly tolerance and volume change of control chamber is analyzed. The optimization model of the assembly is established. The impact of assembly tolerance on injector's performance is simulated according to the optimization algorithm. The simulation result shows that quantity of injection fuel changes correspondingly with the change of assembly tolerance, while injection rate and pressure do not change significantly, and the response rate of needle considerably slow. Similarly, the leakage rate of fuel in control chamber is calculated, indicating that the assembly tolerance has obvious impact on fuel leakage and its rate. The study illuminates that injector's assembly tolerance has prominent effect on injection.
\end{abstract}

Keywords: assembly tolerance, intelligent optimization algorithm, high pressure common rail, simulation

\section{Introduction}

The rigorous exhaust emission legislation and increasingly development of diesel engine electronic control technology make high-pressure common-rail fuel injec- tion system come into the world. It initiates the new era of diesel engine fuel injection technology. As a high flexible fuel injection system, the high-pressure common-rail injection system has become a trend of the diesel engine technology for its remarkable characteristics. Acting as the execution unit, Fuel injector is the

* Corresponding author: shuiyuantang@gmail.com 
key part of a high-pressure common rail fuel injection system. Its structural parameters, manufacturing precision, assembly quality have an important impact on the injecting of the fuel system[1-2]. Based on the structural analysis of the fuel injector, a study on assembly dimension chain of the injector control chamber is conducted. And the impact of assembly tolerance on injector's performance is simulated with Hydsim software. On this basis, the principle of selective assembly for injector assembly is put forward.

\section{The Geometric Model of an Injector}

The common rail fuel injector is made up of an electromagnetic valve, a sealing ball valve, an orifice of oil feeding and return, a control piston, an adjust shim, a press-adjusting spring, a tappet, a combining seat, a needle valve, a needle-valve body, and nozzle nuts[3].
The structural drawing of an injector is shown in the Fig.1.

\section{The Assembly Dimension Chain of the Injector}

\section{Control Chamber}

The control chamber is a key part of a fuel injector, which important parameters include the minimum volume, the diameter and lift of the control piston, the clearance between control piston and control chamber. The motional regulation of the injector needle is decided by the process of pressure variation in the chamber, and the oil injecting rule is fixed[4-5]. The key parameters of the control chamber are theoretically calculated and simulated. According to analysis the impact of relative parameters on the injector fuel injection performance is given out. And it provides theoretical basis for tolerance parameter optimization of the injector control chamber.

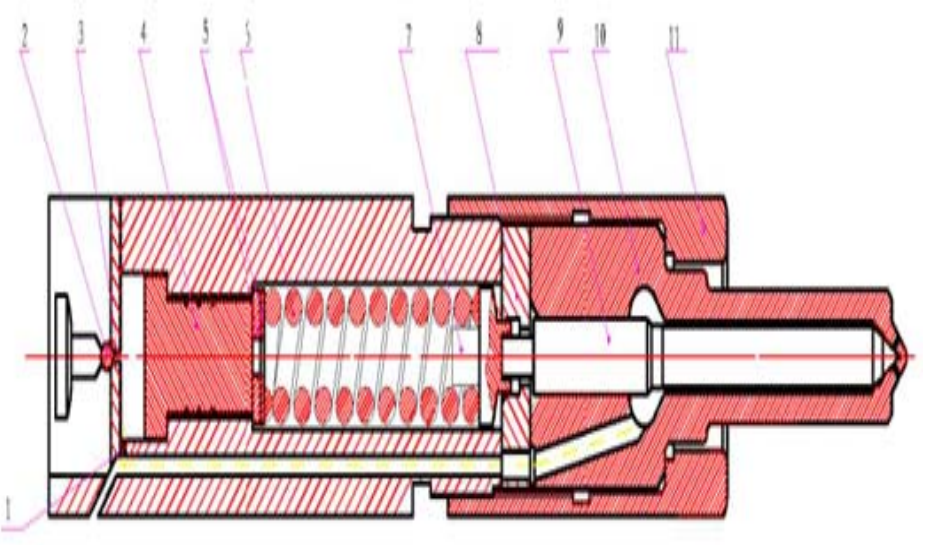

Fig.1 The structural drawing of an injector1-orifice of oil feeding 2-sealing ball valve 3-orifice of oil return 4-control piston 5-adjust shim 6-press-adjusting spring 7-tappet 8-combining seat 9-needle valve 10-needle-valve body 11-nozzle nut

In the Fig.2, there is a assembly dimension chain, which contains the piston length $a_{1}$, the piston chamber length $\mathrm{a}_{2}$ and the maximum lift dimension $\mathrm{a}_{0}$, and $\mathrm{a} 0$ is closedloop. According to the formula of assembly dimension chain, the upper deviation, the lower deviation and tolerance is expressed respectively as the following:

$$
\begin{aligned}
& E S_{0}=E S_{a 2}-E I_{a 1} \\
& E I_{0}=E I_{a 2}-E S_{a 1} \\
& T_{0}=T_{1}+T_{2}
\end{aligned}
$$

Assuming that the machining dimension of piston chamber and piston is $\mathrm{a}_{2}{ }_{2}$ and $\mathrm{a}_{1}{ }_{1}$, the practical machining error is $T_{2}^{\prime}$ and $T_{1}^{\prime}$, then: 


$$
\begin{aligned}
& T_{1}{ }^{\prime}=a_{1}{ }^{\prime}-a_{1} \\
& T_{2}{ }^{\prime}=a_{2}{ }^{\prime}-a_{2}
\end{aligned}
$$

As is illustrated in fig.2, the volume variation of the control chamber is as the following:

$$
\Delta V=\pi *\left(d_{1} / 2\right)^{2} *\left(a^{\prime}{ }_{2}-a^{\prime}{ }_{1}-a_{2}+a_{1}\right)
$$

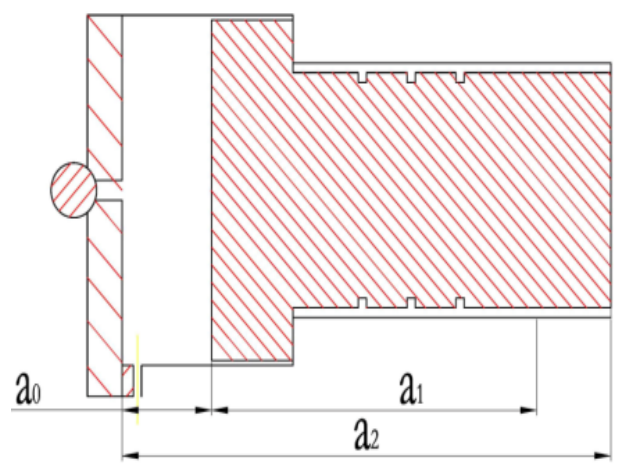

Fig.2 Assembly dimension chain of injector control chamber

\section{Simulation of Injector Characteristic}

\section{1 simulation model of injector}

In this research, the simulation software is Hydsim, which is the professional software in Fuel Injection System of Diesel Engine. The simulation model is established, as shown in fig.3.

In this model, the nozzle adopts the module of "VOC(Extended model)". The needle adopts "Needle(Standard)" module. The control piston adopts "Piston (Standard)" module. The chamber of control piston and accumulator both adopt "Volume (Stan- dard)" module. The leakage of needle valve and piston both adopt "Leakage(Annular Gap)" module. The others of the model adopt common module[6,7,8].

In the previous discussion, the paper focuses on the change of volume of control chamber from the change of tolerance on the axial and radial. In the next, the change of volume because of the tolerance change is

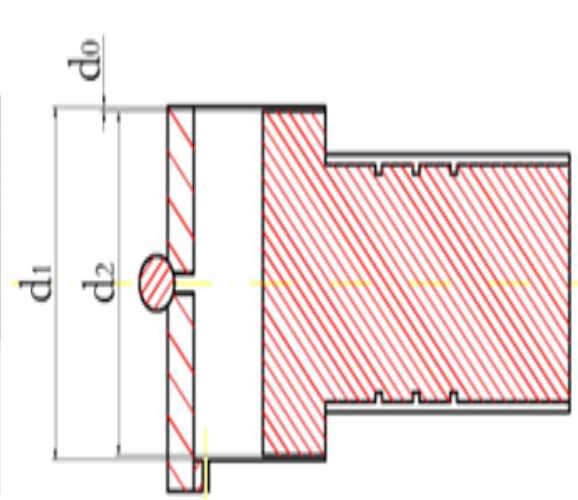

In Fig. 2 the radial dimension chain of control piston and chamber is shown, $\mathrm{d} 1$ is the control-piston diameter, $\mathrm{d} 2$ is the topper-cylinder diameter of control piston, and $\mathrm{d} 0$ is the tolerance clearance between control piston and chamber. analyzed, and the impact to the inject performance is discussed.

\subsection{Simulation of the inject performance for the axial tolerance change of control chamber}

In the axial dimension of the assembly, the tolerance of the closed loop $T_{0}$ is the most important tolerance which must be guaranteed. The tolerance of the compositional loops is divided into a, b, c, d, e, f, g, seven classes[9,10,11]. The tolerance of every class is shown in table.1.

According to the class of tolerance, the volume of control piston and the length of control chamber which are changed for the tolerance change are divided into a, b, c, $\mathrm{d}, \mathrm{e}, \mathrm{f}, \mathrm{g}$, seven classes. In Hydsim, the seven sets of data are entered as input parameters to the control piston and control chamber. The simulation curves of quantity of injector and injection rate and the regulation of the needle movement are shown in Fig. 4, Fig.5, Fig.6 and Fig.7.

As the tolerance of control piston increases within the range of $\mathrm{T} 1$ from $0.01-0.07$ on the one side, the toler- 
ance of control chamber-T2 decreases correspondingly quantity of injection is gradually increasing. from the $0.07-0.01$ on the other side. From the Fig.4, the

Table 1 the tolerance class of the control piston and control chamber

\begin{tabular}{ccc}
\hline Name & $\mathrm{T}_{1}$ & $\mathrm{~T}_{2}$ \\
\hline $\mathrm{a}$ & 0.01 & 0.07 \\
\hline $\mathrm{b}$ & 0.02 & 0.06 \\
\hline $\mathrm{c}$ & 0.03 & 0.05 \\
\hline $\mathrm{d}$ & 0.04 & 0.04 \\
\hline $\mathrm{e}$ & 0.05 & 0.03 \\
\hline $\mathrm{f}$ & 0.06 & 0.02 \\
\hline $\mathrm{g}$ & 0.07 & 0.01 \\
\hline
\end{tabular}

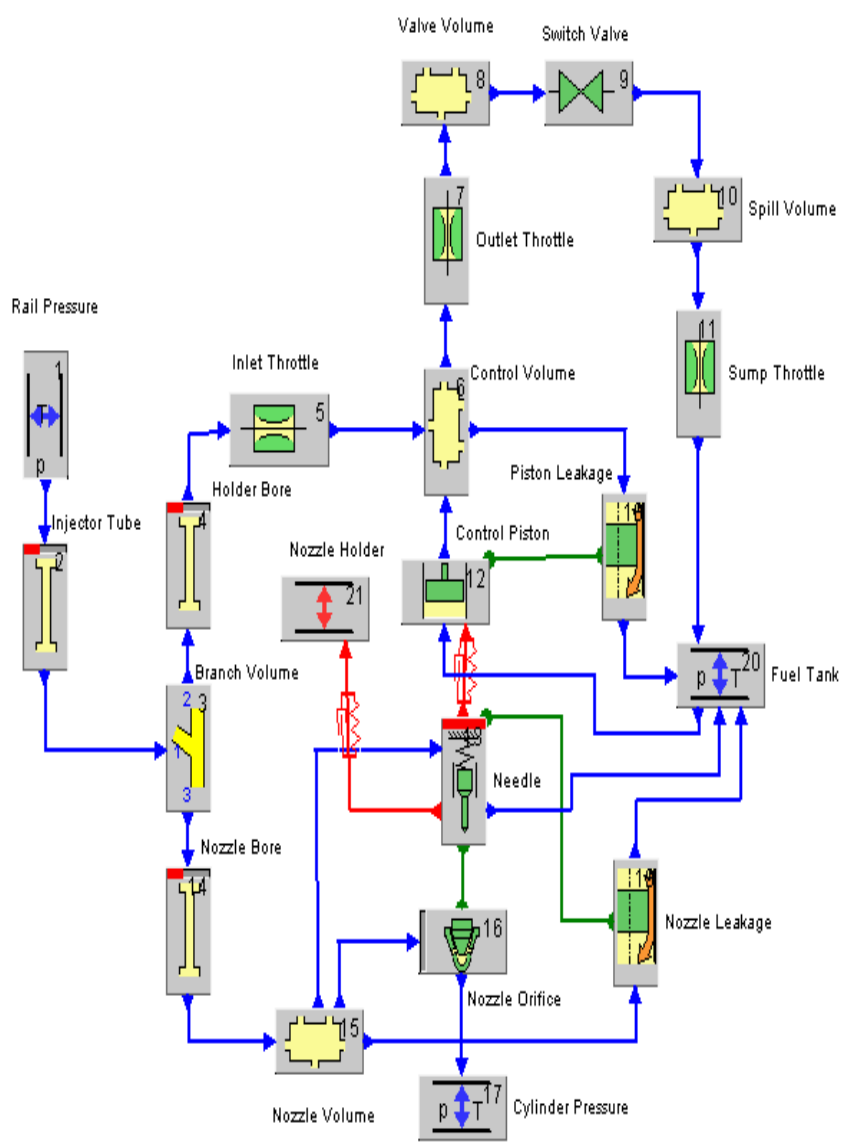

Fig. 3 the simulation model of injector characteristic 


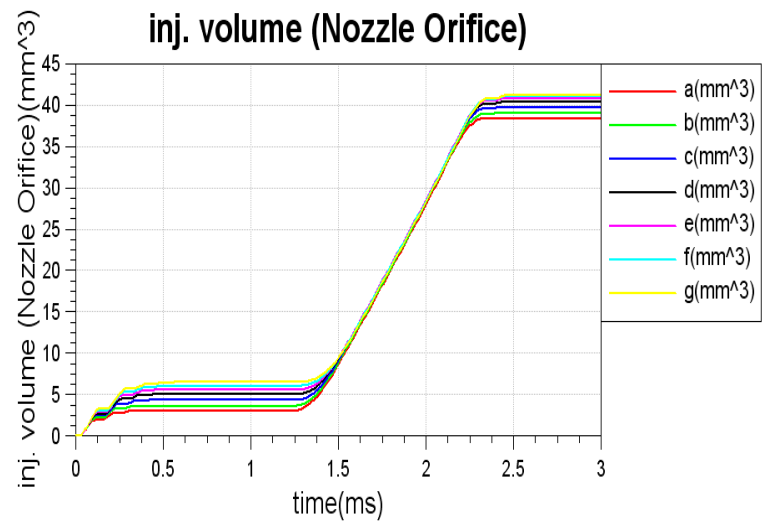

Fig.4 The influence to the fuel injection quantity

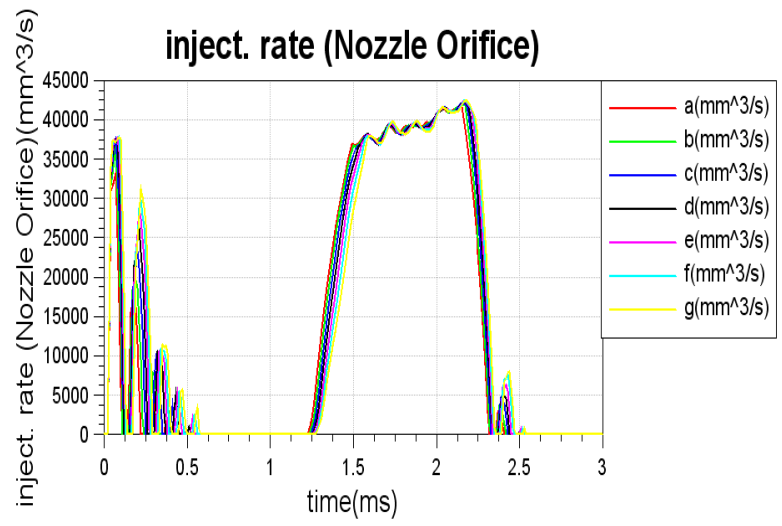

Fig. 5 the influence to the injection rate

In Fig.5 there is no significant change about injection rate, but the starting and ending time are delayed, which meansto increase the response time of injector. In Fig.6, there is no significant change about the pressure in control chamber, as the changes with the tolerance impact on the change of volume is almost negligible to the size of control chamber itself. In Fig. 7 the response rate of needle is significantly slower from the regulation of movement 


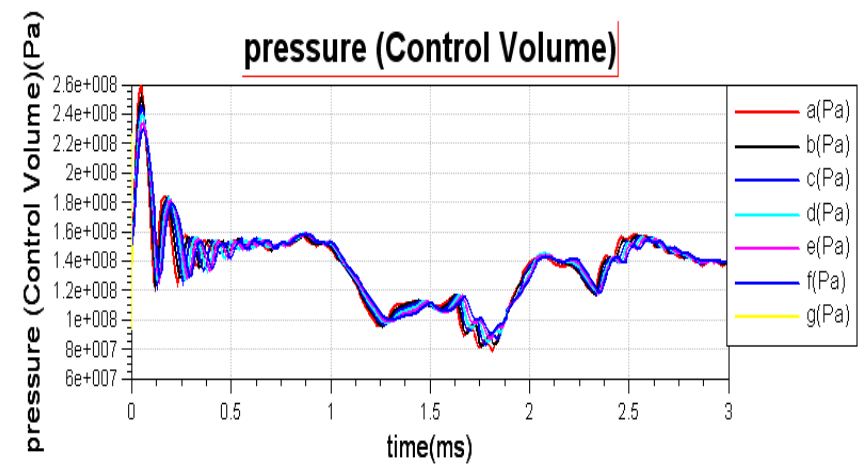

Fig. 6 the influence to the pressure fluctuations

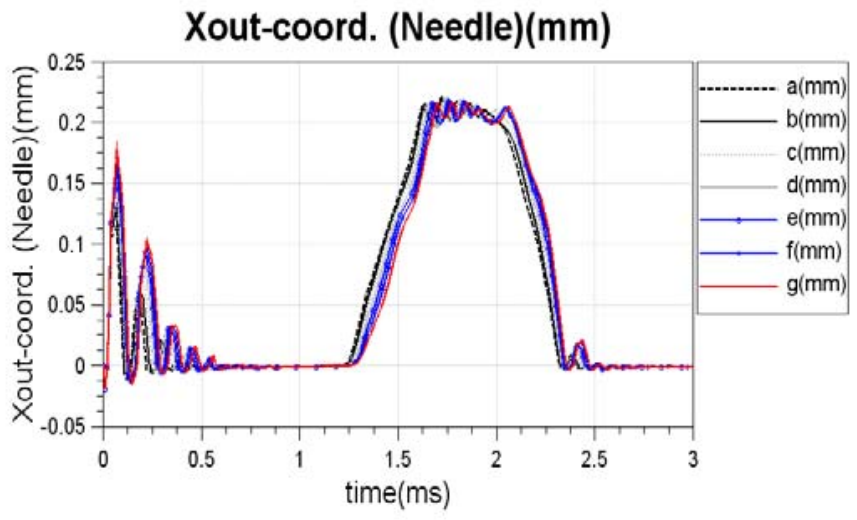

Fig.7 the influence to the needle move

\subsection{Leakage calculation to the control chamber}

According to fluid mechanics knowledge, assume injector needle in the course of the movement has the same lift and speed with the control piston, according to the formula(8), the leakage about the pieces of control piston is calculated.

$$
Q_{c x}=\frac{\pi d_{c}\left|p_{c}-p_{o}\right| \delta_{c}{ }^{3}}{12 \eta l_{c}}
$$

Where dc: the diameter of control chamber $(\mathrm{mm})$; $\delta \mathrm{c}$ : the average gap between the control piston and control chamber ( $\mathrm{mm})$;

lc: the length of mating annular face about the pieces of control piston

$\eta$ : fluid dynamic viscosity

In the formula leakage is proportional to the diameter of control piston and the cube of the gap between the control piston and control chamber, inversely proportional to the length of mating annular face[12,13]. 


\subsection{Simulation for the leakage of control chamber}

Similarly, the pieces of the control piston tolerances in the radial direction is also divided into $a, b, c, d, e, f, g$ seven classes, these classes are shown in table 2.
The simulation model is input with the mating gap, calculated and analyzed[14]. The curves of simulation about the leakage rate and quantity respectively are shown in Fig.8 and Fig.9.

Table 2 the classes for mating gap between the control piston and chamber

\begin{tabular}{cccccccc}
\hline Name & $\mathrm{a}$ & $\mathrm{b}$ & $\mathrm{c}$ & $\mathrm{d}$ & $\mathrm{e}$ & $\mathrm{f}$ & $\mathrm{g}$ \\
\hline Gap & 0.003 & 0.004 & 0.005 & 0.006 & 0.007 & 0.008 & 0.009 \\
\hline
\end{tabular}

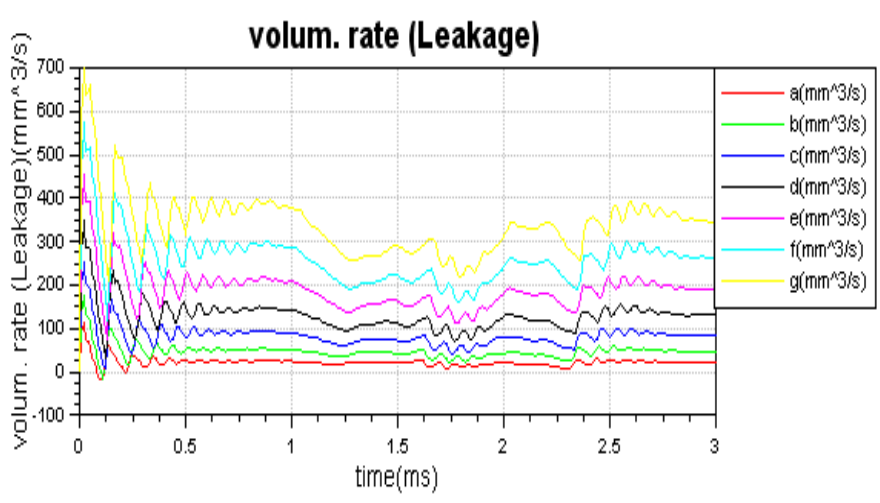

Fig. 8 the leakage rate of fuel in control chamber

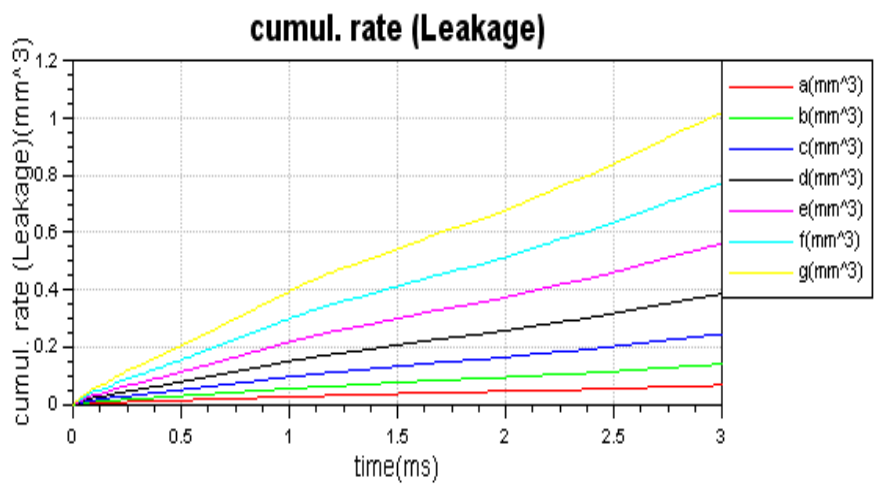

Fig.9 the leakage quantity of fuel in control chamber cess, the process must be reasonable and the assembly

From Fig. 8 and Fig. 9 it can be drawn that the impact tolerances must be strictly controlled. assembly gap has been very clear. In the assembly pro- 


\section{Conclusions}

Based on the theoretical calculation and simulation analysis, the following conclusions can be drawn:

1) When the assembly design tolerance of the control chamber T0 is $0.08 \mathrm{~mm}$, in the case of ensuring the assembly tolerance $T_{0}$, the smaller tolerance of control piston on axial direction is, and the greater tolerance of control chamber on axis direction is, the better the characteristic of the injection system is.

2) For the gap between the control piston and chamber, the tolerance must be strictly controlled in the design value. The simulation results show that if the gap tolerance were increased $0.001 \mathrm{~mm}$, the amount of fuel leaked and leakage rate would be doubly increased.

\section{Acknowledgement}

The authors are grateful to the Project Office of DEDP 1901 of China because of their kind support.

\section{References}

1. Hoffmann K, Maderstein $T$, Peter $T$. The common rail injection system - a new chapter in diesel injection technology. MTZ, 1997, 10:572-582

2. Dong Wei. Effect of rail pressure on start-up characteristic of a high-pressure common rail diesel engine. Chinese Internal Combustion Engine Engineering, 2008(10):11-14

3. Li B.f. Analysis of assembly process affecting injector characteristic. Modern Vehicle Power, 2010(4):51-54.

4. Tang Y L. Experimental investigation on the injection pressure control of GD-1 high pressure common rail diesel engine. Diesel Engine, 2004(6):16-18.

5. Qin Z J. Present situations and development perspective of high-pressure common rail injection system of Bosch company. Tractor \& Farm Transporter, 2006(2):2-6

6. Hlousek. Electronical control fuel injection system for medium speed diesel engine. SAE Paper 981928

7. Deng Dongmi. Injection Fuel System for Diesel Engine[M]. Beijing: China Machine Press, 2009.
8. Ma T S. Improvement of the structure of a diesel engine's fuel injector. Diesel Engine, vol.30(2008) No.1: 32-34

9. He Z X. Numerical simulation of transient flow in high pressure common rail injector. Journal of Jiangsu University, 2007, vol.28 No.2:142-146

10. Cabbar VeyselBaysal, AydanM. Erkmen. An intelligent inference system for robot hand optimal grasp preshaping. International Journal of Computational Intelligence Systems, 2010(10), Vol.3-5:656-673.

11. Liu B B, Li G X. Existing status and trend of high pressure common rail injection system in diesel engine. Internal Combustion Engines, 2006, 22(2): 1- 3.

12. Hlousek J. Common rail fuel injection system for high speed large diesel engine. CIMAC Congress 1998. Copenhagen: 1998: 25- 32.

13. Tzay-Fa Su. An experimental study of high injection pressure diesel sprays [D]. Madison: University of Wisconsin, 1995

14. Wuhong Wang, Hongwei Guo, Katsushi Ikeuchi, Heiner Bubb, Numerical simulation and analysis procedure for digital driving dependability in intelligent transport system, KSCE Journal of Civil Engineering, 2011 15(5),891898. 